\title{
Knowledge, Attitude and Practices of Infection Prevention among Anesthesia Professional at Jimma University Teaching Hospital; Oromia Region, South West Ethiopia, May 2015
}

Kebebe B*, Tefera T, Jisha $\mathrm{H}$

\begin{abstract}
Background: Employing standard precautions for infection prevention is increasingly concerned in operating theater. The KAP of Anesthetists plays a vital role in minimizing the risk of infection in surgical patients.

Objective: To assess knowledge, attitude and practices of Anesthetists' on standard precaution of infection prevention. Methodology: Facility based cross sectional study was conducted in JUTH from MAY 08 -22/2015. Data was collected from all Anesthetists using pretested self-administered questionnaire. The knowledge level, attitude and practice of respondents were analyzed as predefined scale levels using scientific calculator and computer. Finally the result was presented as total percentage using tables and descriptive statements.

Result: Eighteen questionnaires were distributed and 17 (94.44\%) were found to be valid and analyzed. Based on grading of knowledge level $14(82.35 \%)$ of them has good knowledge while the rest of $3(17.64 \%)$ have poor knowledge. Among 17, $14(82.35 \%)$ attitude score was $>15$ and $3(17.64 \%)$ score was below 15 . Therefore $14(82.35 \%)$ Anesthetists have favorable attitude and $3(17.64 \%)$ have unfavorable attitude on standard precaution. Out of $17,4(23.52 \%)$ was exposed and $3(75 \%)$ of them wash with soap and water and use hand antiseptics as immediate measure after exposure.

Conclusion and Recommendation: The majority of Anesthetists had poor practice of hand washing before and between every patient they intended to care. So a continual training program should be arranged for Anesthetists to follow the trend of hand washing with standard protocols for hand hygiene in the health care environment.
\end{abstract}

Keywords: Attitudes; Knowledge; Practice; Infection Prevention; Jimma.

\author{
*Corresponding Author: \\ Bulcha Kebebe, \\ Jimma University, College of Health Science, Ethiopia. \\ Tel: +251920345867 \\ E-mail: bulchakebebe@gmail.com
}

Received: November 20, 2015

Accepted: December 12, 2015

Published: December 16, 2015

Citation: Kebebe B, Tefera T, Jisha H (2015) Knowledge, Attitude and Practices of Infection Prevention among Anesthesia Professional at Jimma University Teaching Hospital; Oromia Region, South West Ethiopia, May 2015. Int J Anesth Res. 3(11), 176-180. doi: http://dx.doi. org $/ 10.19070 / 2332-2780-1500043$

Copyright: Kebebe $\mathbf{B}^{\odot}$ 2015. This is an open-access article distributed under the terms of the Creative Commons Attribution License, which permits unrestricted use, distribution and reproduction in any medium, provided the original author and source are credited.

\section{Introduction}

With the emergence of HIV/AIDS, guidelines for protecting operation room workers from becoming infected with HIV and other blood borne infections (e.g. HCV) were quickly developed and became known as Universal Precautions (UP). But because of many people with blood borne infections such as HIV/AIDS do not have symptoms, nor can they be visibly recognized as being infected, UP had to be modified to include all persons [1].
A new alternative system, called Body Substance Isolation (BSI) were introduced near same time, focused on protecting patients and health care workers from all moist and potentially infected body substances (secretions and excretions), not just blood. BSI was primarily fostering on the use of gloves before touching mucous membranes or non-intact skin, and before anticipated contact with moist body fluids (e.g. blood, semen, vaginal secretions, wound drainage, sputum, saliva, amniotic fluid, etc [2].

Most of these infections can be prevented with readily available, relatively inexpensive strategies by: adhering to recommendation of infection prevention practices, especially hand hygiene and personal protective equipments, paying attention to well-established processes for decontamination and cleaning of soiled instruments and other items, followed by either sterilization or high-level disinfection; and improving safety in operating rooms and other high-risk areas where the most serious and frequent injuries and exposures to infectious agents occur [3, 4].

New guidelines issued by CDC in 1996 involve a two-level approach Standard Precautions, which apply to all clients and patients attending healthcare facilities and Transmission-Based Precautions, which apply only to hospitalized patients. This new system retains features of both universal precaution and body substance isolation. Moreover, it replaces the cumbersome disease-specific isolation precautions with three sets of transmission-based precautions for use in hospitalized patients [5].

Hand hygiene (using an antiseptic or hand rub) after touching 
blood, body fluids, secretions, excretions and contaminated items, immediately after removing gloves, patient precautions were not applied may result in potential of infection [6].

The following universal infection control precautions are advised by the World Health Organization (WHO) to protect operation room workers and clients from blood-borne infections including HIV. Washing hands with soap and water before and after procedures, using protective barriers such as gloves, gowns, aprons, masks, goggles for direct contact with blood and other body fluids, disinfecting instruments and other contaminated equipment, Handling properly soiled linen, Gloves and leak proof bags should be used if necessary. Cleaning should be performed outside patient areas, using detergent and hot water. Using a new, auto disable syringe (AD) or single-use disposable injection equipment for all injections is highly recommended. Sterilizable injection should only be considered if single use equipment is not available and if the sterility can be documented time, steam and temperature (TST) indicators [7].

Operation Room workers, who work in theatre settings, also are at risk of exposure to serious, potentially life-threatening infections. For example, in the US, more than 800,000 needle stick injuries occur each year despite continuing education and vigorous efforts aimed at preventing such accidents [9]. The world health organization (WHO) estimated that at least $50 \%$ of the 12 billion injections administered each year in the developing world are unsafe-posing serious health risk to recipients, health workers and the public $[4,6]$.

A study done in Africa on universal precaution showed that waste disposal was problematic in Chad, Cameron, Cote-de-Voire, Guinea Bissau and Uganda. In these countries there were no health centers that had a facility for safe disposal of used materials. But in Ethiopia, Rwanda, Kenya and Zambia, incineration of used syringes was reported to be the common practice [10].

Study done in Ethiopia at southern nation, nationalities, and peoples region (SNNPR) showed that $32.4 \%$ of health care workers (HCWs) reported as they had sustained at least one form of accidental injury with needle or other sharps [11]. A study done in University of Geneva Hospital in Switzerland revealed that the hand hygiene compliance rate ranges from $23 \%$ to $87 \%$. Overall, doctors practiced proper hand hygiene only 57 percent of the time when opportunities for hand washing arose [12].

Other study done by Nigat project and Engender health in Ethiopia showed that healthcare workers don't usually wash their hands on arrival to work place and before putting on glove; even though, it is well practiced between clients and before leaving work place [13].

Even though extensive studies were done on knowledge, attitude and practices compliance with standard precaution among other health care providers but little was done on anesthetists. Therefore this study aimed to assess about knowledge of SP, attitude towards SP and to assess the gap between the ideal and practical aspect of standard precaution application by anesthetists in the operating room.

\section{Materials and Methods}

Descriptive cross-sectional study was conducted from May 08 to
22, 2015 at Jimma University Teaching Hospital (JUTH), located in Jimma town $350 \mathrm{~km}$ to south west from Addis Ababa; Ethiopia. This hospital is the only specialized hospital and oldest teaching hospital in the region. It provides multi-disciplinary service for 14,000 inpatient and 12,300 out patients through its major departments including: surgery, gynecological and obstetric, internal medicine, pediatric and child health, ophthalmology, dentistry and diagnostic facilities. It has a capacity of about 450 beds, 5 operation theaters, and 1448 health professionals in the different field of study.

Self-answered questionnaire containing open and close ended questions was used to collect data. The question focused on anesthetists' knowledge, attitude and practice of universal precaution of infection prevention validated by WHO and national guideline. The data obtained was compiled, cleansed and analyzed using SPSS v. 16; and the descriptive result presented as percentages of total responses. Ten knowledge questions were asked to know the knowledge status of anesthetists' on standard precaution of infection prevention. The respondent's knowledge was graded as good knowledge for those who responded $>7.5$ questions correctly $>75^{\circ} \%$ and poor knowledge for those responded correctly $<7.5$ or $<60 \%$.

\section{Ethical Clearance}

An official permission letter was obtained before data collection from Jimma University Community Based Education office and hospital administration. After the objective and confidentiality of study explained written consent was obtained from all respondents.

\section{Operational Definition}

Knowledge: Defined as participant, from total knowledge related question, correctly respond less than $60 \%$ categorized as having poor knowledge and $60-75 \%$ categorized as having fair knowledge and greater than $75 \%$ as having good knowledge.

Attitude: Ways of thinking of the study subject about infection prevention. The result will be graded according to Likert scale from 1-5. For response to positive statements, strongly agree score $5 \&$ strongly disagree score 1 . For responses to negative statements strongly disagree score $5 \&$ strongly agree score 1 . Based on this score $>60 \%$ considered as favorable attitude while $<60 \%$ considered as unfavorable attitude, which also include neutral response.

Practice: Experience or way of doing of the study subject regarding to prevent any sort of infection. Those who have no risk practice considered as safe practice. Those who had at least one risk practice considered as unsafe practice; practicing without personal protective equipment uses.

\section{Results}

Out of 18, 17 (94.4\%) respondents questionnaire were found completely filled and valid to be included in analysis. Largest number $(82.4 \%)$ of respondents aged between age $24-35$ (with ranges from $24-54$ years). Fifteen $(88.2 \%$ ) were males and two were females. Most of them serve less than 5 years (Table 1).

All respondents agreed that every health professionals are at risk 
Table 1. Sociodemographic distribution of anesthetists at JUTH, 2015.

\begin{tabular}{|c|c|c|c|}
\hline Respondent's & characteristics & Frequency & Percentage \\
\hline Age (year) & $24-35$ & 14 & 82.4 \\
& $35-44$ & & \\
& $45-54$ & 3 & 17.6 \\
\hline Year of Service & $<5$ & 14 & 82.4 \\
& 6 to 10 & & \\
& 11 to 15 & 3 & 17.6 \\
\hline Sex & male & 15 & 88.2 \\
& female & 2 & 11.8 \\
\hline Training attended & Yes & 8 & 47.05 \\
& No & 9 & 52.94 \\
\hline Needle stick & Yes & 5 & 29.41 \\
Injury & No & 12 & 70.59 \\
\hline Blood exposure/ & Yes & 7 & 41.18 \\
body fluid splash & No & 10 & 58.82 \\
\hline
\end{tabular}

of infection from health facility origin.

Majority of anesthetists had never participated in any training program dedicated to infection prevention after their respective pre-service course. From those who have attended the training programs, seminar accounts the greatest; five out of eight respondents.

All anesthetists indicated that they were using all of the personal protective equipment, except exam glove that has been used by few. The mostly used protective equipment was disposable glove, head cover, boots, gown, and face mask. They were using 100\% and least used personal protective equipment was exam glove 4 $(23.5 \%)$.

\section{Knowledge}

The study revealed $14(82.35 \%)$ of anesthetists have good knowledge while the rest of $3(17.64 \%)$ have poor knowledge with score range of 6 to 9 out of 10 question. Only $12(70.5 \%)$ know the presence of prophylaxis after exposure to contaminated needle and sharp. All participants indicated that they know hand washing affect clinical outcome and necessary even when glove worn.

All respondents showed that the know disease can be transmitted through contaminated needle and sharps. Some of the common diseases known by the participant that could be transmitted by contaminated sharps and needle were 17 (100\%) Human Immunodeficiency Virus (HIV), $2(10 \%)$ tetanus, $17(100 \%)$ hepatitis B viruses (HBV), 9 (60) hepatitis $C$ viruses. Among the respondents $13(76.47 \%)$ know that HBV can persist on the external environment for up to seven days.

\section{Attitude}

The study showed from 17, 14 (82.35\%) anesthetists' attitude score was $>15$ and one $(17.64 \%)$ score was below 15 with range of score from 12 to 22 out of 25 questions. Over all 13 (82.35\%) anesthetists have favorable attitude and $3(17.64 \%)$ have unfavorable attitude on standard precaution. Most of the respondents strongly agree on gloves use for all patient care $13(76.5 \%)$, as they can acquire HIV through their in the absence of SP $12(70.5 \%)$ are strongly agree and health care associated organisms are commonly resistance to alcohol $12(70.58 \%)$ are strongly disagree (Ta- ble 2).

Majority of the respondents' use PPE for all people followed by for procedures that need PPE for prevention of body fluid and blood contact.In most of the respondents HIV is the first disease that comes to respondents mind when the issue of infection prevention is raised (Table 3 ).

\section{Practice}

Though they believe the importance of cleaning hands; only 5 $(29.41 \%)$ anesthetists clean their hands between every patient contact. However, 12 (70.5\%) did not clean their hand between every patient they encounter. The result also revealed that the practice of anesthetists on hand cleaning before and after touching patient $4(23.5 \%)$ and $5(29.41 \%)$ respectively. Anesthetists those using water and soap as method hand cleaning account 14 $(82.35 \%)$ followed by alcohol based hand rub 3 (17.64\%). Almost $12(70.58 \%)$ has no any risk practice (safe) and $5(29.4 \%)$ have at least one risk practice (unsafe) with what standard precaution recommends. All respondent at least use three personal protective equipment like boots, mask, gloves, gown, cape, etc; while they are doing in health care facility (Table 4).

The entire respondents $17(100 \%)$ clean laryngoscope between every patient they encounter. Majority $12(70.5 \%)$ of the respondents soak the laryngoscope in disinfectants for ten minutes and $4(23.5 \%)$ and $1(5.88 \%)$ of them soak the laryngoscope for five and twenty minutes respectively.

As respondents indicated Berekina is the most frequently used chemical for decontamination and chlorine is the least used. It accounts $9(52.94 \%)$ and followed by alcohol 6 (35.29\%). Only and $5(29.4) \%$ anesthetists wash their gown twice a week while rest 12 $(70.58) \%$ respondent wash once per week.

Out of four anesthetists exposed to blood or body fluids majority three of them wash with soap and water, and then use hand antiseptics as immediate measure after exposure and one respondent washed with only soap and water.

Among the respondents, 8 (47\%) had participated in training program dedicated to infection prevention after their respective preservice course. Of the training programs seminar accounts the 
Table 2. Knowledge of anesthetists regarding infection prevention; JUTH, Ethiopia; 2015.

\begin{tabular}{|c|c|c|}
\hline \multicolumn{1}{|c|}{ Knowledge questions } & \multicolumn{2}{|c|}{ Correct response } \\
\cline { 2 - 3 } & Number of respondents & percentage \\
\hline Hand washing is necessary after every patient contacted & 17 & 100 \\
\hline Hand washing affect clinical outcome of patients & 17 & 100 \\
\hline Hand washing is necessary even when gloves worn & 15 & 88.23 \\
\hline Hepatitis virus can persist for 7 days on human surface & 13 & 76.47 \\
\hline Disease can transmitted through contaminated needle and sharps & 17 & 100 \\
\hline There is prophylaxis after exposure to contaminated sharps & 12 & 70.58 \\
\hline Reuse of syringe is recommended & 17 & 100 \\
\hline
\end{tabular}

Table 3. Attitude of JUTH Anesthetists on standard precaution of infection prevention; Ethiopia 2015.

\begin{tabular}{|c|c|c|c|c|c|c|c|c|c|c|c|}
\hline \multirow{2}{*}{ Statement of attitude } & \multicolumn{9}{|c|}{ Response of participants } \\
\cline { 2 - 13 } & Strongly agree & \multicolumn{2}{|c|}{ Agree } & \multicolumn{2}{|c|}{ Uncertain } & \multicolumn{2}{c|}{ Disagree } & \multicolumn{2}{c|}{ Strongly disagree } \\
\cline { 2 - 13 } & No & $\%$ & No & $\%$ & No & $\%$ & No & $\%$ & No & $\%$ \\
\hline Gloves use for all patient care contact & 13 & 76.5 & 4 & 23.5 & - & - & - & - & - & - \\
\hline $\begin{array}{c}\text { You can acquired HIV through your pro- } \\
\text { fession }\end{array}$ & 10 & 58.82 & 4 & 23.5 & 3 & 17.6 & - & - & - & - \\
\hline $\begin{array}{c}\text { Health facility can be source of infection \& } \\
\text { epidemic in the absence standard precau- } \\
\text { tion. }\end{array}$ & 12 & 70.58 & 5 & 29.4 & - & - & - & - & - & \\
\hline $\begin{array}{c}\text { Health care associated organisms are com- } \\
\text { monly resistant to alcohol }\end{array}$ & 2 & 11.76 & 3 & 17.64 & - & - & 12 & 70.58 & - & - \\
\hline $\begin{array}{c}\text { Your client have acquired HIV through the } \\
\text { service they get in your health facility }\end{array}$ & 11 & 64.7 & 2 & 11.76 & 2 & 11.76 & 1 & 5.88 & 1 & 5.88 \\
\hline
\end{tabular}

Table 4. Situation in which Anesthetists consider to uses PPE for infection prevention at JUTH; Ethiopia, 2015.

\begin{tabular}{|c|c|c|c|}
\hline & Characteristic & Number & Percent \\
\hline Use PPE & For all people & 14 & 82.35 \\
\hline & For only HIV suspected care & - & - \\
\hline & For only HIV positive patient & - & - \\
\hline & For procedure suspected blood/body fluid contamination & 3 & 17.64 \\
\hline Disease & For every patient & - & - \\
\hline & HIV AIDS & 15 & 88.2 \\
\hline & HBV & 10 & 58.8 \\
\hline & HCV & 2 & 11.76 \\
\hline
\end{tabular}

greatest $(52.9 \%)$ (Table 5).

\section{Discussion}

All the respondents 17 (100\%) know that dirty needle and contaminated sharp materials agent could transmit disease causing agent. The commonest disease that is known to be transmitted by health care workers includes HIV 17 (100\%), HCV 12 (70.5\%) and HBV 17 (100\%). Study conducted in the North-West region of the UK also shows that most respondents have changed their practice since the recognition of $\mathrm{HIV}(74.8 \%)$ and hepatitis $\mathrm{B}$ and $\mathrm{C}(69.8 \%)$ are the common disease transmitted by contaminated sharps and needle [19]. As current study reveals knowledge of Anesthetists on HIV and HBV transmission by contaminated sharps and needle is $100 \%$. This may due to government resolution to reduction of HIV in the country as whole.
The study shows that $14(82.35 \%)$ of Anesthetists have favorable attitude and $3(17.64 \%)$ have unfavorable attitude on standard precaution. This shows that the majority of Anesthetists have positive attitude toward the principles of universal precaution. The study reveals that $12(70.58 \%)$ of Anesthetists wash their gown once per week and $5(29.41 \%)$ twice per week which less than research done in SNNPR in which $22.3 \%$ wash their gown twice [12]. This may be explained by having more than one gown by health professionals in which $\mathrm{s} /$ he changes $1^{\text {st }}$ day worn gown at middle of the week and have same day schedule for washing. The study reveals that most Anesthetists had poor practice of hand washing before and between every patient contact which is in-line with the study done by Nigat project and Engender health in Ethiopia showed that healthcare workers don't usually wash their hands on arrival to work place and before putting on glove. Even though, it is better practiced between clients and before 
Table 5. Hand washing Practices of Anesthetists at JUTH; Ethiopia, 2015.

\begin{tabular}{|c|c|c|c|c|}
\hline \multirow{2}{*}{ Statements } & \multicolumn{3}{|c|}{ Response frequency } \\
\cline { 2 - 4 } & Yes & Percentage & No & Percentage \\
\hline Do you clean your hand before touching patients & 4 & 23.5 & 13 & 76.47 \\
\hline Do you clean your hand after touching patients & 5 & 29.41 & 12 & 70.5 \\
\hline Method of hand cleaning; using & Number of respondents & Percentage & \\
\hline plain water \& soap Antimicrobial & 14 & 82.35 & \\
\hline Alcohol based hand rub plain water only & 3 & 17.64 & \\
\hline
\end{tabular}

leaving work place. But the survey done in Pakistan shows, only $18 \%$ of respondents stated that they always washed their hands after every patient contact $[13,19]$. This may be due to limited number health professionals given chance to be trained on how to practice. The study result shows, all Anesthetists 17(100\%) were using disposable glove, gown, head cover, mask and boots in their everyday practice. But in Australian and New Zealand anesthetists, only $37 \%$ always wore gloves while administering anesthetics and in Pakistan, thirty four percent of the respondents always used masks, and only $9 \%$ used gloves in their everyday practice $[17,18]$. As current study reveals the standards precaution for hand hygiene as they pertain to the practice of anesthesiology and modern innovations in using of PPE procedures and products that improve the opportunities for anesthesiologists to employ safe hand hygiene [14].

As the study reveals that $23.52 \%$ of Anesthetists had blood or body fluid splash to their eyes and $3(75 \%)$ wash with soap and water and use hand antiseptics immediate measure after exposure and also $29.41 \%$ of Anesthetists had needle or sharp injury and didn't report which was the same with research in Australian and New Zealand thirty-nine percent had needle stick injuries in the preceding 12 months; 43\% did not always report them [17].But in Nigeria ninety-six percents of all respondents will initiate an action after a needle stick injury whilst $4 \%$ will ignore [16]. Among 17 Anesthetists $8(47 \%)$ had participated on training program dedicated to infection prevention after their respective pre-service courses and $9(53 \%)$ hadn't trained. This may be due to limited number of Anesthetists given chance to be trained at once from the hospital.

\section{Conclusion}

Though JUTH anesthetists had a better knowledge and attitude their practices is very poor against standard precaution of infection prevention.

There are no clear standards for all activities especially for proper handling and disposing of used needles/sharp materials, cleaning reusable materials (laryngoscope, corrugated tube, endotracheal tube, etc.), personal protective equipment and hand washing.

Therefore the concerning body should arrange up to date training and manuals regularly for professionals and work on capacity building to improve their practices to the standards of infection prevention practices.

\section{References}

[1]. Centers for Disease Control (CDC) (1985) Recommendations for preventing transmission of infection with human T-lymphtropic virus type III/ lymphadenopathy-associated virus in the workplace. MMWR 34(45): 681686, 691-695.

[2]. Lynch P, Jackson M, Preston GA, Soule BM (1998) Infection Prevention with Limited Resources: A Handbook for Infection Committees. ETNA Communications, Chicago.

[3]. Patterson JE, Vecchio J, Pantelick EL, Farrel P, Mazon D, et al. (1991) Association of contaminated gloves with of Acinetobacter calcoaceticus var. anitratus in an intensive care unit. Am J Med 91(5): 479-483

[4]. Simonsen L, Kane A, Lloyd J, Zaffran M, Kane M (1999) Unsafe injection in the developing world and transmission of bloodborne pathogens: a review. Bull World Health Organ 77(10): 789-800.

[5]. Garner JS (1996) Guideline for isolation precautions in hospitals. The Hospital Infection Control Practices Advisory. Infect Control Hosp Epidemiol 17(1): 53-80.

[6]. Collins CH, Kennedy DA (1987) Microbiological hazards of occupational needle stick and 'sharps' injuries. J Appl Bacteriol 62(5): 385-402.

[7]. Tietjen LG (1997) Preventing infections in healthcare workers. Outlook 15(4): $1-4$.

[8]. Lacerda RA (2003) infeccaohospitalas e suarelacaocom aevolucao das practicas de assistencia a saude. saopaulo; atheeu 9-23.

[9]. Rogers B (1997) Health hazards in nursing and health care: An overview. Am J Infect Control 25(3): 248-261.

[10]. Ministry of Health (2005) Infection prevention guidelines for health care. Facilities in Ethiopia. 1-79.

[11]. Gebriel YW, Tesfaye F (2004) Assessment of safety of injection and related medical practice in health institutions at Sidama Zone, SNNPRS. MPH thesis.

[12]. Karen Pallarito (2004) Doctors Skimp on Hand Hygiene. Health on network foundation. http://www.cdc.gov/od/oc/media/pressrel/fs021025.htm

[13]. Nigat project and Engender health. Stigma or discrimination and infection prevention practices in health care settings. 2003 (Unpublished). Ministry of Health. Infection prevention guidelines for health facilities in Ethiopia. 2005 (Unpublished)

[14]. Katz JD (2004) Hand washing and hand disinfection: more than your mother taught you. Anesthesiol Clin North America 22(3): 457-471

[15]. Carbonne A, Veber B, Hajjar J, Zaro-Goni D, Maugat S, et al. (2006) Evaluation of practices involving a cross infection risk in anaesthesia. Ann Fr Anesth Reanim 25(11-12): 1158-1164.

[16]. Kushimo OT, Akpan SG, Desalu I, Merah NA, Ilori IU (2007) Knowledge, attitude and practices of Nigerian anaesthetists in HIV infected surgical patients: a survey. Niger Postgrad Med J 14(3): 261-265.

[17]. Richards MJ, Jenkin GA, Johnson PD (1997) Universal precautions: attitudes of Australian and New Zealand anaesthetists. Med J Aust 166(3): 138-140.

[18]. Yaqub KM, Tariq M, Janjua SK, Masroor R, Safdar A, et al. (2007) A survey of infection control practices of consultant anesthesiologists in teaching hospitals of pakistan. Journal of the College of Physicians and Surgeons-Pakistan 17(9): 523-526.

[19]. el Mikatti N, Dillon P, Healy TE (1999) Hygienic practices of consultant anaesthetists: a survey in the north-west region of the UK. Anaesthesia 54(1): 13-18.

[20]. Rosenberg AD, Bernstein DB, Bernstein RL, Skovron ML, Ramanathan S, et al. (1995) Accidental needle sticks: do anesthesiologists practice proper infection control precautions? Am J Anesthesiology 22(3): 125-132.

[21]. Charuluxananan S, Migasena R, Somboonviboon W, Chinachot T, Kunthollaxami A (2000) Effect of national seminar on AIDS and anesthesia upon knowledge, attitude and practice concerning HIV among Thai anesthesia personnel. J Med Assoc Thai 83(2): 174-181.

[22]. Tait AR, Tuttle DB (1994) Prevention of occupational transmission of human immunodeficiency virus and hepatitis $B$ virus among anesthesiologists: a survey of anesthesiology practice. Anesth Analg 79(4): 623-628. 